\title{
UNBALANCED SOMATIC CHROMOSOMAL VARIATION IN CREPIS
}

M. NAVASHIN 


\section{University of California Publicattons in Agricultural Sclences}

Volume 6, No. 3, pp. 95-106, plates 4 and 5, 2 figures in text Issued Mareh 19, 1930

\section{University of California Press \\ BerkFlaty, Catifornia}

\section{Cambridge University Preiss}

London, EngLand 


\section{UNBALANCED SOMATIC CHROMOSOMAL VARIATION IN CREPIS}

BY

M. NAVASHIN

\section{INTRODUCTION}

It is a well-known phenomenon that the chromosomal constitution may vary during the somatic cycle of development. Numerous instances have been described for various representatives of the two organie kingdoms. The majority of such phenomena may be divided into two principal groups, viz., chromosomal chimeras and chromosomal variegation. In chromosomal chimeras, entire shoots, branches, groups of similar tissues, different tissues, or finally, groups of cells within the same tissue, differ in their chromosomal composition. Various kinds of chimeras may be of oceasional occurrence, whereas in certain cases a chimeral condition constitutes a constant typical feature of the organism. Thus, the tetraploid shoots known to occur in Datura (Blakeslee and Belling, 1924) and the so-called mosaies in Drosophila (Morgan, Bridges and Sturtevant, 1925) represent chimeral conditions of occasional oceurrence. Constant differenees in the chromosomal constitution of different tissues of certain insects (Frolowa, 1928) or in the root tips of hemp (Breslawetz, 1926) may be referred to as typical features of certain organisms.

Extreme chimeral conditions, in which separate little groups of cells of different chromosomal constitution are oceasionally found in normal tissues, represent transitional stages to chromosomal variegation. The distinction between the two kinds of variation depends obviously upon the degree of mutability. If variation occurs infrequently, the resulting chromosomal constitution becomes fixed in long lineages of cells and a chimera arises. If, on the contrary, the frequency of variation is very high, no definite lineage of cells can possibly arise, and variegation is the result.

In Crepis investigations, many cases of vegetative chromosomal variation have been observed, the great majority of them being located in the root tips. They were mostly of the balanced type, i.e., they represented various grades of polyploidy of definite sectors of cells or 
of individual cells. Tetraploid cells were found, for instance, in the root tips of C. dioscoridis (MI. Navashin, 1926) and of a hybrid derivative of $C$. biennis $\times$ C. setosa. (Iollingshead, 1928a). Giant polyploid cells containing as many as $128 n$ chromosomes were found in $C$. tectorum (M. Navashin, loc. cit.). Many instances of various grades of polyploidy of ehimeral type were found by the present writer and by Miss Gerassimova in several Crepis species and in interspecifie hybrids. Finally, it was found in haploid individuals of C. capillaris (Hollingshead, 1928b; Babcock and Navashin, 1930) that a very considerable proportion of cells become diploid, the latter circumstance even leading to the formation of diploid shoots (Hollingshead, loc. cit.).

As was stated above, the majority of observations concern the root tips. It was found many times by the present writer that different roots taken from the same plant differed in their chromosomal constitution. Thus in many instances entire tetraploid roots were found to occur, together with normal ones, in diploid individuals of $C$. tectorum and C. capillaris. Furthermore, in plants possessing small extra fragments or other chromosomal abnormalities, certain roots were found to be entirely normal as regards their chromosomes. Finally, eases were found when a single plant vielded roots of three different ehromosomal types; and hybrid derivatives possessing one foreign ehromosome produced some roots without that extra chromosome. All these and similar observations, however, were mostly explained as experimental errors, i.e., as due to oceasional confusion of roots belonging to different individuals, a circumstance eventually taking place. All these cases, however, conld by no means be explained as mere results of errors. On the contrary, by taking special precautions it was found that the majority, if indeed, not all of them should be attributed to actual variation in somatic eycle.

In the cultures of the past year (1929) one plant was found which was undoubtedly of unbalanced chimeral trpe. Not only its roots but the upper parts of the shoots as well differed in their chromosomal constitution. The description of this interesting chimera, the discussion of its mode of origin and of the bearing of chromosomal variation on some problems of general importance constitute the principal subject of this paper.

It gives the writer special pleasure to acknowledge the excellent help given during the course of the investigation by Miss II. N. Gerassimova. 


\section{AN UNBALANCED CHROMOSOMAL CHIMERA IN}

\section{C. tectorum L.}

Numerous progenies of triploids in $C$. tectorum have been grown and subjected to investigation by the writer since 1926. Among several cultures grown in 1929 in Moseow in the experimental garden of the Timiriazev Federal Institute of Scientific Research, one, namely culture 29.1013, contained the plant which is described below. This particular plant 29.1013-40 was investigated cytologically, and root tips were taken from it in the young rosette stage. Altogether twentysix roots were investigated. Nineteen of them proved to be triplo- $B$ simple trisomic, the remaining seven showing wholly normal diploid
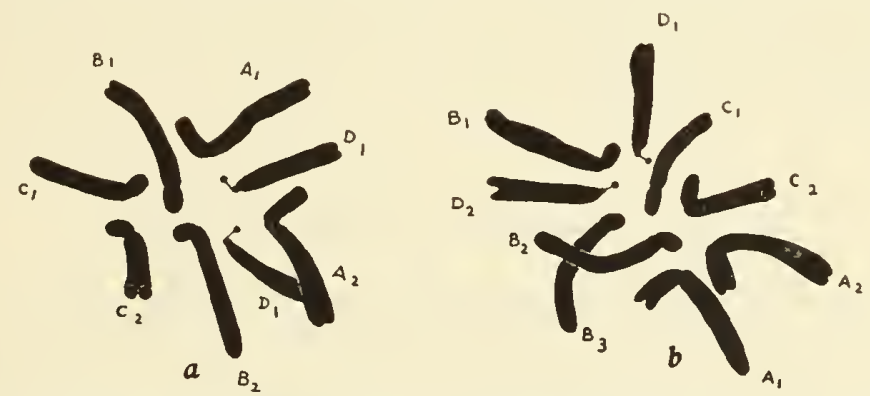

Fig. 1. Somatic metaphases: $a$, of the normal (diploid) component; $b$, of the trisomie component (note the extra B-chromosome). Root tips. $\times 2400$.

chromosomal complement (fig. 1). This first result of the investigation strongly suggested the conclusion that the plant in question was a sectorial chimera with one part trisomic and the other normal diploid.

Further observations have shown the correctness of this conclusion. After the shoots had developed it appeared that they were of two clearly distinct types. Two of them were undoubtedly triplo-B simple trisomic ("diamond"), the third being of typical normal appearance. The trisomic shoots were (as is common for trisomics) about lialf as tall as the normal component and possessed the typical "diamondshaped" leaves which are the best morphological characteristics of the triplo-B type. The flowering heads, buds, and fruiting heads were much smaller in the dwarf component as compared with the tall one. This difference in head size is again a constant distinction between the triplo- $\mathrm{B}$ trisomies and normal plants. The cytological investiga- 
tion of the young meristem of the flower buds and of the root tips, taken separately from the two components, proved beyond any question that the plant really was a trisomic-normal, sectorial chimera. Thus nine chromosomes were found in the buds and root tips of the dwarf component whereas those of the tall component had only the four pairs, typical of the somatic garniture in C. tectorum. (See pls. 4 and 5 and fig. 1.)

As noted above, the two components of the chimera did not differ morphologically in any way from the respective entire plants of corresponding chromosomal constitution. With regard to their physiological behavior, the trisomic portion did not show any marked peculiarities, but the "normal"' diploid component was entirely different from the thousands of diploid $C$. tectorum plants that had been previously seen. In contrast to them, it was of very low fertility, a phenomenon never met with in normal individuals of $C$. tectorum. The cause of this low fertility of the "normal" component could not be detected. No irregularities in meiosis in P.MI.C. were found.

\section{MODE OF ORIGIN OF TIIE CHIMERA}

The chimera described above occurred in the progeny of a triplo-A simple trisomic plant derived from a triploid parent. The appearance of an extra B-cliromosome should be attributed, therefore, to elimination of the extra A-chromosome followed by duplication of the B-chromosome, most likely through equational non-disjunction. Cases of the latter sort were observed many times by the writer when certain chromosomes in hybrids were duplicated, obviously through equational non-disjunction. As for the origin of the chimeral condition, two principal ways are feasible; first, through diembryony, and second, through somatic elimination of the extra chromosome sometime during early development; at any rate prior to the formation of flowering shoots. The first manner of origin is highly improbable as might be easily slown. Thus, in order to account for the occurrence of two cytologically different embryos in the same achene, one may suggest the three following possibilities: the formation of an adrentitious embryo from the vegetative tissue, or of two functional embryo sacs in the same ovule, or finally of two functional ovules in the same ovary. Occurrence of adventitious embryo is a phenomenon never met with in Crepis and, furthermore, it could by no means account 
either for the formation of a normal diploid embryo or for that of a triplo-B trisomic. It could give rise only to an individual identical with the original plant, i.e., a triplo-A trisomic. Two embryo sacs in the same ovule occasionally occur in Crepis; likewise instances have been found where a double ovule is formed. In such cases, however, the second embryo sac is situated at the chalazal end of the orule and could hardly be fertilized, for the simple reason that the pollen tube coukd never reach it. Also, the double ovules are most probably incapable of development; never were embryos found to be contained in them.

Thus it seems that the most probable way to explain the origin of the chimera is to admit the somatic elimination of the extra chromosome which could give rise to the normal diploid shoot. ${ }^{1}$ Unbalanced somatic chromosomal variation is known to occur in Datura (Blakeslee and Belling, loc. cit.) and is strongly suspected in many other cases.

With regard to the mechanism of somatic chromosome elimination, some observations of the present writer on phenomena found in root tips in $C$. tectorum may throw light on the problem. The results of these observations are given below.

\section{CHROMIOSOMAL VARIEGATION in C. tectorum}

Among several hundred seedlings grown from seed obtained from a normal $C$. tcctorum plant, one was found that showed a striking peculiarity, namely, the meristematic cells of its root tip differed in various ways one from another in their chromosomal constitution.

Furthermore, the most outstanding features of this individual was that its chromosomes not only differed in number in different cells of the root tip but that some of them were atypically built. These atypical chromosomes, instead of being rod-shaped, were the shape of rings or disks. In early prophases they appeared like broad rings formed by a thread of the same diameter as the remaining normal ehromosomes of the same nucleus. In later stages the rings became progressively contracted while thickening of the thread and narrow-

1 One could suppose, on the contrary, addition of the third B-chromosome leading to the formation of trisomic shoots by a normal diploid plant. The results of eytological investigation have shown, however, that the majority of the roots were trisomic (see above). Moreover, two shoots were trisomic and only one, diploid. All this makes it most probable that the plant in question was originally a triplo- $\mathrm{B}$ trisomic and that in the course of development it produced one diploid shoot through elimination of the extra chromosome. 
ing of the central clear space took place. At the metaphase the space within the rings usually disappeared entirely so that the rings assumed the form of more or less regular disks. In no stages of development did these structures differ in their staining reactions from the ordinary chromosomes. In one case the two daughter strands composing a normal chromosome failed to separate in the anaphase. In the few telophases observed, the atypical chromosomes resulted in two identical
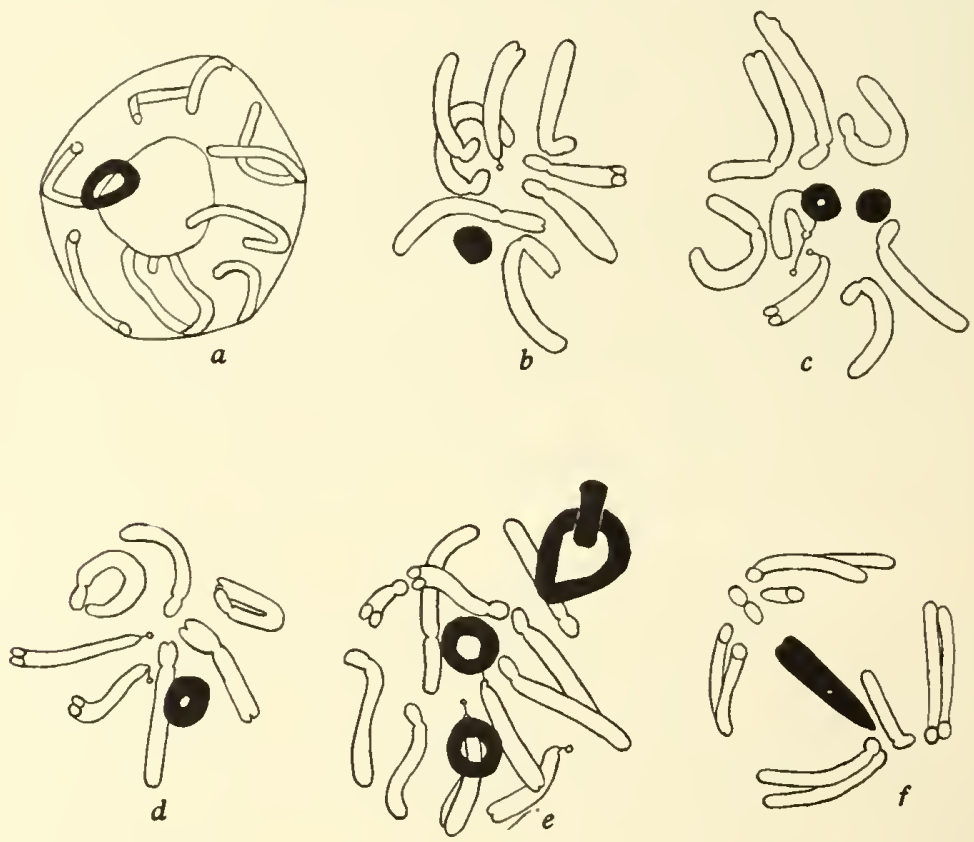

Fig. 2. Chromosomal variegation in C. tectorum. $\times 2400$.

$a$, prophase showing one "ring"; $b$, metaphase showing eight chromosomes plus one "disk," note the absence of the second satellited chromosome, which has been either transformed into the "disk" or replaced by a non-homologous chromosome; $c$, metaphase showing nomal diploid complement plus one "ring", and one "disk", $d$, metaphase showing seven ehromosomes plus one "ring"; $e$, incomplete tetraploid metaphase showing four "rings," two of them united in a fashion of chain links; $f$, late anaphase showing one lagging chromosome which failed to divide into daughter halves.

bodies situated like the ordinary telophasic chromosomes at the two opposite poles of the cell. Thus there was hardly any doubt that one was dealing with real chromosomes modified in their organization in such a way that the ends of the cliromosomes, instead of being free, became united thus forming a closed ring.

These peculiar chromatin structures varied in number in different cells. The number of the remaining normal chromosomes varied as 
well. There were found cells which contained normal diploid eliromosome sets plus one or two ring-shaped chromosomes extra; those containing nine normal chromosomes plus one "ring" extra; those with seven normal chromosomes and one "ring" extra. Finally, polyploid (probably tetraploid) cells were found which contained a varying number of "rings" along with the normal chromosomes; sometimes there were as many as five "rings." In addition to all these cases of variable chromosomal composition, cells with entirely normal diploid complement were not infrequent. (See fig. 2.)

The distribution of the cells of different chromosomal constitution appeared to be more or less a random one. It was evident that the process of chromosomal variation in this plant took place frequently and probably often in opposite directions in subsequent generations resulting from the same cell. Consequently no long lineage of cells of identical chromosomal constitution could possibly be established, and a typical variegation resulted.

\section{DISCUSSION}

On the basis of the above data, it may be considered as proved that unbalanced somatic chromosomal variation actually takes place in Crepis. The ease deseribed of chromosomal variegation in C. tectorum slows that some disturbances in the chromosomal mechanism may lead both to addition and subtraction of individual chromosomes even in cells elosely related by descent. Although only one actual case of failure of daughter chromosomes to disjoin was observed (cf. fig. $2 f$ ), the occurrence of cells of different chromosomal constitution in the immediate progeny of the same cell indicates that such or some similar process must be not infrequent. Otherwise one is compelled to admit the possibility of the formation of chromosomes de novo or of the disappearance of same, a statement which is against all cytological knowledge. On the contrary, the most probable assumption is that some chromosomal disorder, like that described above, makes it impossible for the chromosomes to function normally, and leads from time to time to addition (duplication) or to subtraction of certain chromosomes. These conditions may arise only for a short period of time, perlaps even only in one cell and may lead to the formation of long lineages of cells of aberrant chromosomal constitution. A chimeral individual may arise in such a case. If, on the contrary, the dis- 
turbance persists in the tissue, no definite chromosomal constitution can be established and variegation takes place.

The plenomenon of somatic chromosomal variation throws some light upon certain problems of general interest. Thus it is very probable that occasional addition or subtraction of individual chrcmosomes unay be responsible for "bud variation" of various kinds as has been suggested by various writers (ef. review by Chittenden, 1927). Balanced chromosomal variation may represent a legitimate condition of specialization of certain tissmes. Somatic variation of high frequency like that described above for $C$. tcctorum may result in chromosomal variegation. And, if genes of visible claracters are involved in it, genetic variegation would be the result. In certain cases true somatic segregation may take place, namely, if one allelomorphic chromosome be replaced by another through the addition of one chromosome followed by the subtraction of another. Thus homozygous branches may eventually be produced by a heterozygous individual without any "reverse gene mutation"' at all.

One feature of the described chromosomal chimera deserves special cmphasis. As was pointed out above, the "normal" component possessed a greatly reduced fertility in spite of its normal chromosomal composition and completely healthy condition. It should be concluded, therefore, that the trisomic component exerted some influence on the "normal" component that led to the reduction of its reproductive power. This clearly indicates that not only the similarity or dissimilarity of the genes contained in the allelomorphic chromosomes but some other internal conditions as well may control fertility. Investigation is in progress.

\section{SUMIIARI}

1. Among many plants of a triploid progeny of Crepis tcetorum L. one sectorial chromosonal chimera was found. It consisted of three shoots, two of which were triplo-B simple trisomic ("diamond"), the third being normal diploid. The trisomic component did not differ in any way from the complete trisomic plants of the corresponding type. The "normal" component was morphologically identical with the ordinary diploid plants of the same species but differed from them in that its fertility was greatly reduced.

2. A case of "chromosomal variegation" in C.tectorum is described. This phenomenon consists in a highly frequent variation in chromo- 
somal constitution leading to formation of scattered cells differing in various ways in their chromosome contents. The process of chromosomal variation goes on lere in either direction, i.e., either addition or subtraction of definite chromosomes takes place in subsequent cell generations.

3. The origin of the described sectorial chimera is explained by loss of the extra B-chromosome early in development. The variation in chromosomal composition took place only once, thus establishing a lineage of cells of new chromosomal type. Frequent variation making it impossible for the cell progenies to establish certain definite stable chromosomal constitution leads to variegation.

4. It is suggested that somatic chromosomal variation may lead under some circumstances to "bud variation" or even to true somatic segregation if one allelomorphic chromosome of a heterozygous individual is replaced by another through, a process similar to that described for the "rariegated" individual of $C$. tectorum. Genetic variegation may possibly also depend upon chromosomal variegation.

\section{LITERATURE CITED}

Babcock, E. B., and Navashin, M.

1930. The genus Crepis. Bibliographia Genetica, 6:1-86.

Blakessex, A. F., and Betlling, J.

1924. Science, 60:19-20, cited from L. Sharp, An Introduction to Cytology (New York, 1927).

Breslatwetz, L.

1926. Polyploide Mitosen bei Cannabis sativa L. Ber. Deutsch. Bot. Ges., $44: 498-502$.

Chit thindein, R. J.

1927. Vegetative segregation. Bibliographia Genetica, 3:355-442.

Frolowa, S.

1928. Die Polyploidie einiger Gewebe bei Dipteren. Zeitschr. Zellforsch. mikr. Anat., 8:542-65.

HGLLINGSHEAD, L.

1928a. Chromosomal chimeras in Crepis. Univ. Calif. Publ. Agr. Sci., 2(12): $543-54$.

1928b. A preliminary note on the occurrence of haploids in Crepis. Am. Nat, $62: 282-84$.

Morgan, T. H., Bribges, C. B., and Sturtevant, A. H.

1925. The Genetics of Drosophila. Bibliographia Genetica, 2:1-262.

Navashin, M.

1926. Variabilität des Zellkerns bei Crepis-Arten in Bezug auf die Artbildung. Zeitschr. Zellforsch. mikr. Anat., 4:171-215. 


\section{PLATE 4}

General view of the chimera 29.1013-40 of Crepis tectorum L. Two trisomic shoots (left) and one normal shoot (right). Note the difference in the leaf shape, in the habit of growth, and in the general development of the two components. The plant was taken from the ground just before the photograph was made. Natural size circa. 


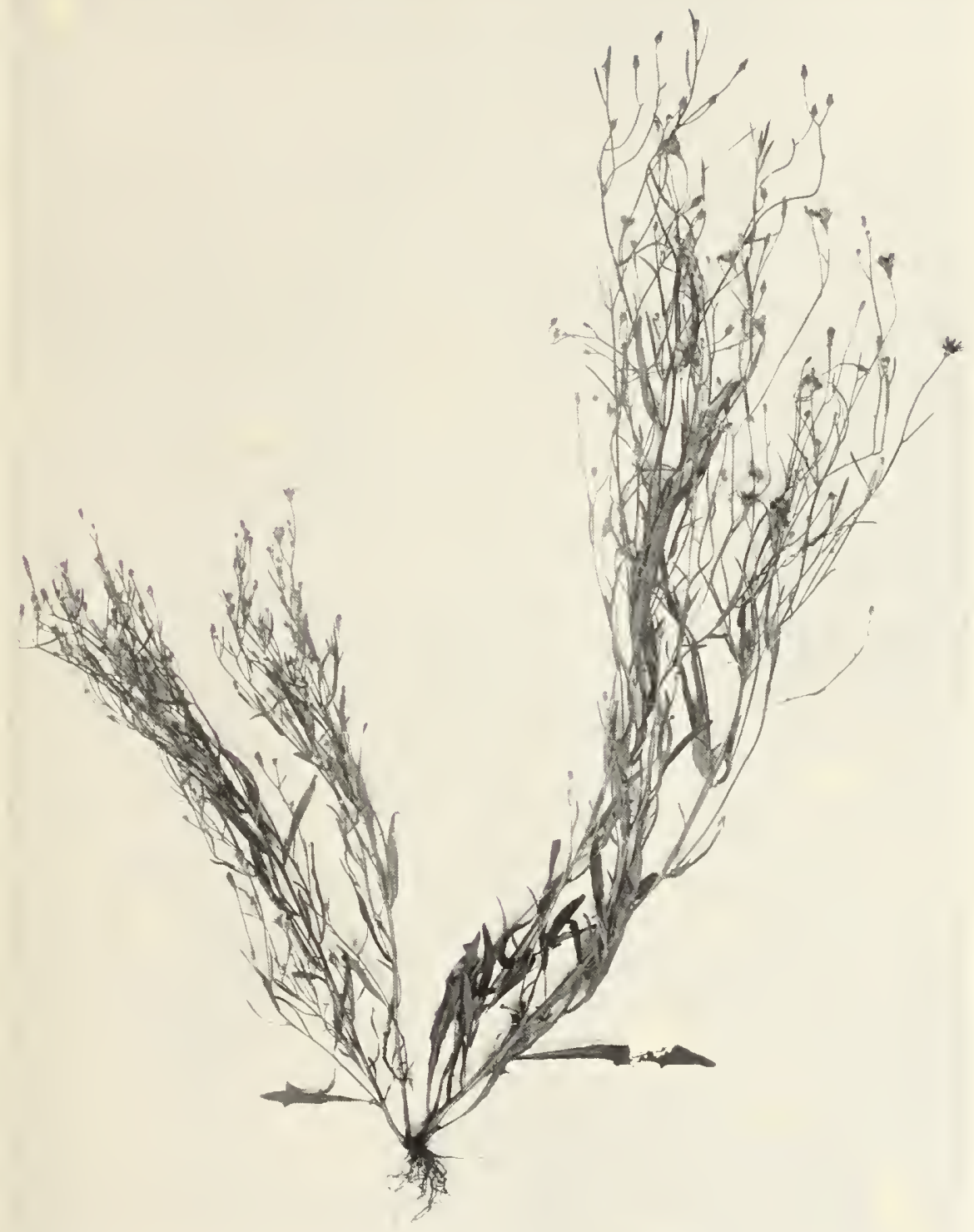






\section{PLATE 5}

Some details of the same elimeral plant. Below, the lower part of the chimera showing the robust stem of the normal component and the weak slender stems of the trisomic component. The mode of connection between the two components elearly indicates that the formation of the diploid (normal) sloot must have taken place very early in the development.

Above, buds, flowering and fruiting capitula of the trisomic component (left) as compared with those of the normal component (right). Natural size circa. 

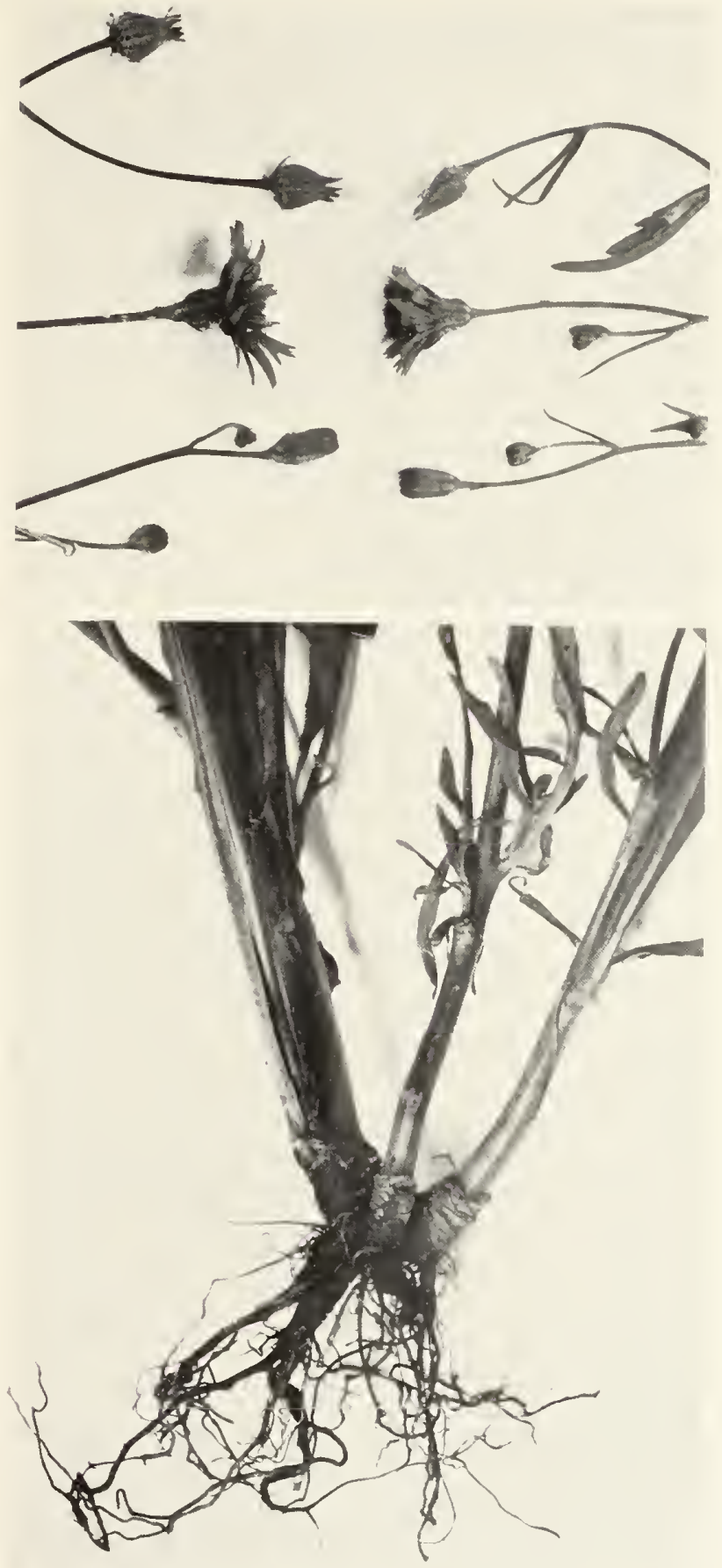
